\title{
First Report on the Host Programme: Pilot Projects in London, Winnipeg and Regina
}

\section{Summary of Findings 1}

The objective of the host programme is to enhance the settlement process of those government-assisted refugees and other designated persons who qualify for support under the federal Adjustment Assistance Programme (AAP). This objective is to be achieved by matching these persons or families with host groups. The host groups are expected to assist refugees in settling more quickly, in learning English or French, in obtaining employment as soon as possible, and in providing friendship and emotional support. The Adjustment Assistance Programme currently provides funds to government-assisted refugees including those in the "control" programme. Funding is similar to provincial welfare assistance. Also allowan-ces are paid to acquire basic clothing and furniture. This assistance is available to refugees for a maximum period of one year following arrival in Canada. If, at some time during that period, the refugee becomes self-sufficient through employment, AAP funding ceases thereby.

Funding to a maximum of $\$ 50,000$ in each community is provided to established community organizations. A programme coordinator is responsible for recruiting and training host groups, matching them with incoming refugees and monitoring and supporting their activities. With programme co-ordinators in daily contact with the community, awareness of the refugee situation is enhanced.

The purpose of this report is to determine whether the host group is meeting its objectives. Two sample groups, host group and "control" refugees, were set up in each of the three communities (London, Winnipeg and Regina). Data were collected for the first six months of the programme.

\section{History of the Programme}

Authority was granted to transfer funds from the AAP to the host-group programme in

1 This is an adapted and edited version of the report issued in August, 1986, by Policy and Programme Development, Employment and Immigration Canada.
1985. Host projects were initiated in London, Winnipeg and Regina in March 1985. Since then, six more pilot projects have begun in Quebec City, Kitchener, Windsor, Saskatoon, Calgary and Vancouver. (The present evaluation treats the programme only in the initial three cities which began after a sixmonth delay caused by organizational difficulties.)

\section{Sample Selection}

In each of the three cities, London, Winnipeg and Regina, the Canada Employment Commission (CEC) created sample groups of 35 host-group refugee and 35 "control" refugee group units (individuals or families). Refugees in the "control" portion of the sample were selected from government-sponsored refugees who arrived during the same period as those in the host group. Both sample groups were eligible to receive all the services normally provided government-sponsored refugees in the community.

The two sample groups (host group and "control") were matched as far as possible in each community by age range, gender of household head, mix of geographic origin and family size, so that comparisons could be made of two groups from roughly equivalent backgrounds. Overall, more than $75 \%$ of the refugees in the study are male. The largest proportion of refugees comes from a Southeast Asian background, with those from Central American and European region ranking second and third, respectively. Among the host-group refugees, family size is larger, with the control group representing single persons and smallersized families in greater frequency.

This report is preliminary. As the refugees in this pilot programme had been resident in the community for six months of less, there was insufficient time to demonstrate the full effect of the host group programme on settlement. For example, at the time of data compilation (early 1986), no difference appeared between those refugees matched with host group and refugees in the "control" group with respect to rate of employment. Fewer than $20 \%$ of the total sample were employed; most were still enrolled in language training.

\section{Social Adaptation Criteria}

\section{Accommodation}

Most refugees, whether host or "control" group, moved into permanent accommodation within the first week in the community. Few differences are apparent: refugees showed a longer period in temporary accommodations, especially in Winnipeg, where matching with host groups did not occur until after the refugee had moved into permanent accommodation.

\section{Language Acquisition}

Not all refugees receive language training. It is provided only to those whose facility is judged to be insufficient to gain employment (approximately $80 \%$ of both host group and "control" samples). Data on language acquisition show three benefits of the host group programme. First, retention in the programme was higher among host-group refugees. Only $3 \%$ of the host group dropped out of language training, as compared with $15 \%$ of the "control" refugees. Secondly, some $32 \%$ of the host group refugees reported that their English improved rapidly, as compared with $13 \%$ of the "control" group. Thirdly, nearly $70 \%$ of the matched group reported "very frequent" or "frequent" use of English, as compared with only 55\% of the "control" group.

\section{Adjustment Assistance Programme Contributions}

At the end or the first reporting period, fewer than $20 \%$ of all refugees were employed. The majority have not been in the country long enough to have completed language training -- a normal prerequisite to seeking employment. Host groups appear, however, to become actively involved directly or indirectly in the job-search process. Of the seven host-group refugees in the London sample who are employed, four found employment through their host group. Host groups also assist refugees in preparing for the job market.

\section{Employment}

At the end of the first reporting period, fewer than $20 \%$ of all refugees were employed. The 
majority have not been in the country long enough to have completed language training -- a normal prerequisite to seeking employment. Host groups appear, however, to become actively involved directly or indirectly in the job-search process. Of the seven host-group refugees in the London sample who are employed, four found employment through their host group. Host groups also assist refugees in preparing for the job market.

\section{Canada Employment Commission Involvement}

There are no clear differences between the host group and "control" group in terms of the number of visits of a refugee to the CEC offices. Canada Employment Commission officers have reported, however, that refugees in the host groups visit less often and that the interviews are brief. Most routine communityrelated questions come less frequently from host groups.

\section{Social Adaptation}

Both host-group and "control" refugees have a low level of knowledge about community services, with the exception of health facilities. In Winnipeg, however, most of the host-group refugees showed awareness of social agencies and day care. Few of the "control" group indicated any knowledge of these areas. Consumer behaviour (shopping) is rather well developed, especially among host groups. Use of other community services has been limited among all refugees, again with the exception of health facilities.

Almost all refugees who responded to the questionnaire express satisfaction with the rate of their resettlement. Generally, more hostgroup refugees express happiness with the rate of resettlement. Refugees matched with host groups have more Canadian friends. Some $89 \%$ of the host-group refugees, compared with $44 \%$ of the "control" group, reported having Canadian friends. Differences are less marked for acquaintances; $80 \%$ of the host-group refugees, and $64 \%$ of the "control" group refugees reported having acquaintances who are Canadian. A greater proportion of host-group refugees also report having neighbours who come from their former country.

\section{Relocation}

Relocation to another city in Canada was infrequent, involving $10 \%$ of all refugees. Nearly $90 \%$ of the movers were in the "control" group refugee sample. They offered a variety of reasons for relocation, e.g., join friends, job, etc.

\section{Community Awareness}

Spontaneous comments by hosts and others contacted during the evaluation exercise suggest that the host-group programme has a positive impact upon the local community. As hostgroup co-ordinators are in daily contact with the community, a better understanding of refugees and their situation develops even though those contacted in the community may not be involved in the programme as host-group members or otherwise.

\section{Suggestions for Improvement}

The host-group programme appears to be well designed and is operating smoothly. The programme co-ordinators' reports contain the following ideas for enhancing effectiveness and relieving the heavy workload for co-ordinators:

1. Communication between programme coordinators, CEC counsellors and Canada Employment and Immigration Commission (CEIC) regional offices should be increased for the purpose of improving programme planning.

2. Co-ordinating agencies should be responsible for financial accounting and control rather than the programme coordinators. Also, financial monitoring by CEIC should be increased.

3. A local advisory committee should be established to give direction and assistance to the programme co-ordinator.

4. The CEIC national office should develop promotional materials to foster consistency of community awareness and understanding of the Host Programme. This support and information mechanism would eliminate the need for agencies to develop their own individual packages.

5. The CEIC national office should produce background information on different refugee groups to assist programme coordinations in training host groups.

6. More refugees with special needs should be brought into the country under the Host Programme. It is well designed to assist refugees with special needs.

No major changes were suggested for the structure of the programme.

\section{Analytical Considerations}

While both Regina and London matched refugees with host groups within one week of arrival in Canada, Winnipeg matched refugees with host groups after they had already been in the country for several weeks. In all areas of the study, the impact of the host groups will be less, the longer the time period between arrival and matching.

Owing to different times of arrival of refugees and staging of the evaluation, the "after six months" evaluation criterion was made more flexible. In Winnipeg, for example, the majority had been in the community for more than nine months at the time of the evaluation, whereas most of those in Regina had been in the community for less than three months. The range of length of stay of "control" group refugees varied between three and eight months. All areas of the analysis are thereby affected. The matched group would not have had the same opportunity to show signs of adaptation as would the "control" group. Among the differences, a sample group that has been in the country longer will show lower average AAP contributions (per-person per-week) than would a group with a shorter stay.

The response rate for questionnaires sent to refugees was low in all communities, especially among those in the "control" groups. This differential may be due to the assistance which the host-group refugees were able to receive from the host-group members.

\section{Conclusion}

The host group is showing a very positive trend in terms of language acquisition and frequency of use of English. There is also a lower drop-out rate among the host-group refugees. In the longer term, language acquisition is expected to result in higher employment and general adaptation. Very few in the matched group have relocated to other communities since their arrival. Also most of the matched group indicates having Canadian friends and acquaintances. These factors indicate a higher level of integration into the community for the host group as compared with the "control" group. Reports from the CEC's and host-group co-ordinators illustrate clearly that the host-group project is increasing community awareness of the refugee situation. This effect will have a positive impact on how all immigrants are accepted by Canadians, which in turn will be reflected in the immigrants' increased ability to integrate into Canadian society. 